\title{
Classification of 'Nocardioides fulvus' IFO 14399 and Nocardioides sp. ATCC 39419 in Kribbella gen. nov., as Kribbella flavida sp. nov. and Kribbella sandramycini sp. nov.
}

\author{
Yong-Ha Park, ${ }^{1}$ Jung-Hoon Yoon, ${ }^{1,2}$ Yong Kook Shin, ${ }^{1}$ \\ Ken-ichiro Suzuki, ${ }^{3}$ Takuji Kudo, ${ }^{3}$ Akio Seino, ${ }^{1}$ Hong-Joong Kim, ${ }^{1}$ \\ Jung-Sook Lee ${ }^{1}$ and Sung Taik Lee ${ }^{2}$
}

\begin{abstract}
Author for correspondence: Yong-Ha Park. Tel: +82428604620 . Fax: +82428604625 . e-mail: yhpark@kribb4680.kribb.re.kr
\end{abstract}

\footnotetext{
1 Korean Collection for Type Cultures (KCTC), Korea Research Institute of Bioscience and Biotechnology (KRIBB), PO Box 115, Yusong, Taejon, Korea

2 Department of Biological Sciences, Korea Advanced Institute of Science and Technology, Taejon, Korea

3 Japan Collection of Microorganisms, The Institute of Physical and Chemical Research (RIKEN), Wako-shi, Saitama 351-01, Japan
}

\begin{abstract}
By 165 rDNA sequence analysis, two strains identified previously as members of the genus Nocardioides, namely 'Nocardioides fulvus' IFO 14399 and Nocardioides sp. ATCC 39419, were found to form lines of descent distinct from the genus Nocardioides. Therefore, the two strains were studied taxonomically in detail by phenotypic, particularly chemotaxonomic, characterization, and by phylogenetic analysis including other related taxa. The genomic DNA G+C contents of ' $N$. fulvus' IFO 14399 and Nocardioides sp. ATCC 39419 are 70 and $68 \mathrm{~mol} \%$, respectively. The two strains contain LL-diaminopimelic acid as the diamino acid in their peptidoglycan, together with L-alanine at position 1 of the peptide subunit. The predominant menaquinone found in the two strains is $M K-9\left(\mathrm{H}_{4}\right)$. The major cellular fatty acid found in the two strains is anteiso- $\mathrm{C}_{15: 0}$ which is a minor component of members of the genus Nocardioides. The diagnostic polar lipid of the two strains is phosphatidylcholine. A phylogenetic tree was constructed which showed that the two strains form evolutionary lineages distinct from other LL-diaminopimelic-acid-containing taxa such as, for example, the genus Nocardioides. On the basis of our data, a new genus, Kribbella gen. nov., and two new species, Kribbella flavida gen. nov., sp. nov. and Kribbellla sandramycini gen. nov., sp. nov., are proposed. It is also proposed that the new genus be included in the family Nocardioidaceae.
\end{abstract}

Keywords: Kribbella flavida, Kribbella sandramycini, Nocardioides spp., LL-diaminopimelic acid, phylogeny

\section{INTRODUCTION}

Relatively few bacterial genera containing LLdiaminopimelic acid (LL-A ${ }_{2} \mathrm{pm}$ ) in the cell wall peptidoglycan are known when compared to the number of genera containing meso-diaminopimelic acid. However, the number of such taxa has recently been considerably increased. The actinomycete genera containing LL-diaminopimelic acid in the cell wall fall in five phylogenetic lineages that represent five families

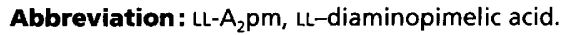

The GenBank accession numbers for the 16S rDNA sequences of 'Nocardioides fulvus' IFO 14399 and Nocardioides sp. ATCC 39419 determined in this work are AF005017 and AF005020, respectively. within the class Actinobacteria (Stackebrandt et al., 1997): (i) Streptomyces (Waksman \& Henrici, 1943) (Streptomycetaceae); (ii) Sporichthya (Lechevalier et al., 1968; Rainey et al., 1993) (Sporichthyaceae); (iii) Nocardioides (Prauser, 1976) and Aeromicrobium (Miller et al., 1991) (Nocardioidaceae); (iv) Intrasporangium (Kalakoutskii et al., 1967), Terrabacter (Collins et al., 1989) and Terracoccus (Prauser et al., 1997) (Intrasporangiaceae); (v) Propioniferax (Yokota et al., 1994), Luteococcus (Tamura et al., 1994), Microlunatus (Nakamura et al., 1995) and Friedmanniella (Schumann et al., 1997) (Propionibacteriaceae). In this study, a new genus containing LLdiaminopimelic acid in the peptidoglycan is proposed. 16S rDNA sequence analysis shows that two strains identified previously as members of the genus 

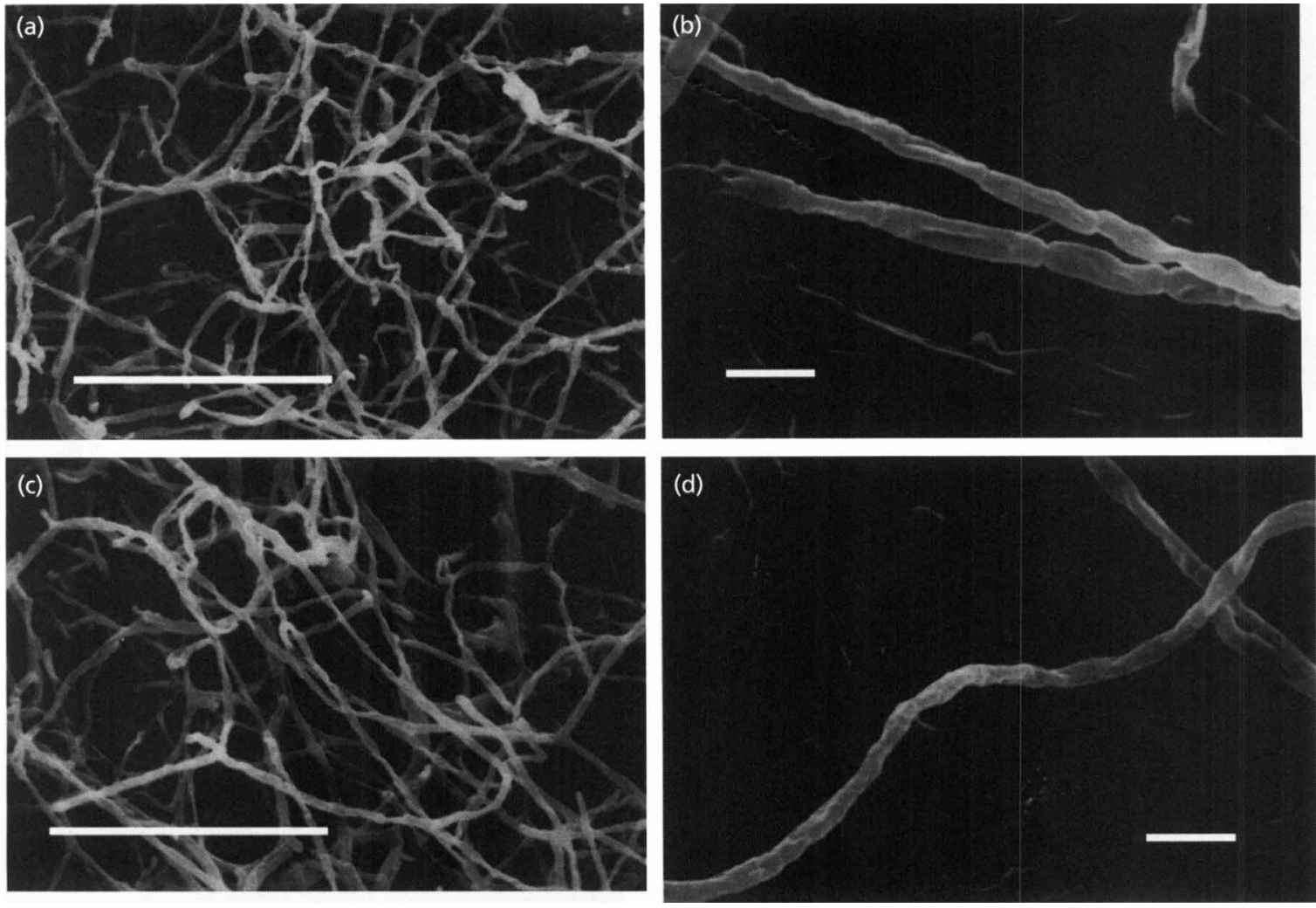

Fig. 1. Scanning electron micrographs of aerial mycelia of 'Nocardioides fulvus' IFO 14399 and Nocardioides sp. ATCC 39419. (a, b) 'N. fulvus' IFO 14399. Bars, $10 \mu \mathrm{m}$ (a) and $1 \mu \mathrm{m}$ (b). (c, d) Nocardioides sp. ATCC 39419. Bars, $10 \mu \mathrm{m}$ (c) and $1 \mu \mathrm{m}(\mathrm{d})$.

Nocardioides, namely 'Nocardioides fulvus' IFO 14399 (Ruan \& Zhang, 1979) and Nocardioides sp. ATCC 39419 (Matson \& Bush, 1989) form phylogenetic lineages distinct from Nocardioides species. Therefore, we investigated the phenotypic characters of these two strains to determine their taxonomic positions. On the basis of our data, we propose that they should be established as members of a new genus, Kribbella gen. nov.

Nesterenko et al. (1985) proposed the family Nocardioidaceae to accommodate the genera Nocardioides (Prauser, 1976) and Pimelobacter (Suzuki \& Komagata, 1983). However, three Pimelobacter species were transferred to the genus Nocardioides or reclassified as the genus Terrabacter (Collins et al., 1989). Before the proposal of Nesterenko et al. (1985), O'Donnell et al. (1982) proposed that Arthrobacter simplex (Pimelobacter simplex) should be assigned to the genus Nocardioides as $N$. simplex. Pimelobacter jensenii was transferred to the genus Nocardioides as $N$. jensenii and Pimelobacter tumescens was reclassified in the new genus Terrabacter as T. tumescens (Collins et al., 1989). T. tumescens was shown to be distantly related to the genus Nocardioides from phylogenetic inference based on 16S rRNA sequences (Collins et al., 1989; Tamura \& Yokota, 1994). Therefore, the genus Nocardioides was the only member of the family
Nocardioidaceae before the genus Aeromicrobium was included in the family (Stackebrandt et al., 1997).

The genus Aeromicrobium, which is phylogenetically related to the genus Nocardioides, was proposed by Miller et al. (1991). In our study, the new genus, Kribbella was found to be phylogenetically related to the genera Nocardioides and Aeromicrobium despite differences in some chemotaxonomic characters and formation of lines of descent distinct from the genera Nocardioides and Aeromicrobium. It is thought appropriate that the genera Nocardioides and Aeromicrobium and the new genus Kribbella are grouped in a single family. Therefore, we propose that the new genus is included in the family Nocardioidaceae.

\section{METHODS}

Bacterial strains and culture conditions. ' $N$. fulvus' IFO 14399 and Nocardioides sp. ATCC 39419 were ususally cultivated at $30^{\circ} \mathrm{C}$ on International Streptomyces Project (ISP) medium no. 2, which contains $\left(1^{-1}\right) 4 \mathrm{~g}$ yeast extract, $10 \mathrm{~g}$ malt extract and $4 \mathrm{~g}$ glucose ( $\mathrm{pH} \mathrm{7 \cdot 3)}$. The two strains were also cultivated on nutrient agar (Difco), trypticase soy agar (Difco), glucose-asparagine agar (Lindenbein, 1952) and ISP agar media nos 1, 3, 4, 5 and 7 (Shirling \& Gottlieb, 1966) to examine the morphological characteristics. The two strains and some reference strains were also grown for $4 \mathrm{~d}$ on nutrient agar (Difco) for fatty acid methyl ester (FAME) 
Table 1. Utilization of various compounds as sole carbon and energy sources by Nocardioides albus KCTC 9186', 'Nocardioides fulvus' IFO 14399 and Nocardioides sp. ATCC 39419

+ , Positive reaction; -, negative reaction; w, weakly positive reaction.

\begin{tabular}{|c|c|c|c|}
\hline Compound & $\begin{array}{c}\text { N. albus } \\
\text { KCTC } 9186^{\mathrm{T}}\end{array}$ & $\begin{array}{l}\text { 'N. fulvus' } \\
\text { IFO } 14399\end{array}$ & $\begin{array}{l}\text { Nocardioides sp. } \\
\text { ATCC } 39419\end{array}$ \\
\hline L-Arabinose & + & - & w \\
\hline $\mathrm{D}(+)$-Galactose & + & - & + \\
\hline D( - )-Ribose & + & - & + \\
\hline $\mathrm{D}(+)$-Glucose & + & + & + \\
\hline $\mathrm{D}(-)$-Fructose & + & - & + \\
\hline $\mathrm{D}(+)$-Mannose & + & - & + \\
\hline $\mathrm{D}(+)$-Xylose & + & - & + \\
\hline$\alpha$-L(+)-Rhamnose & + & - & + \\
\hline $\mathrm{D}(+)$-Cellobiose & + & + & + \\
\hline Lactose & + & - & + \\
\hline Maltose & + & + & + \\
\hline$\alpha$-D(+)-Melibiose & - & + & + \\
\hline Sucrose & + & + & + \\
\hline $\mathrm{D}(+)$-Trehalose & - & + & + \\
\hline $\mathrm{D}(+)$-Melezitose & - & + & + \\
\hline $\mathrm{D}(+)$-Raffinose & - & + & + \\
\hline Adonitol & - & + & + \\
\hline myo-Inositol & - & + & + \\
\hline D-Mannitol & + & + & + \\
\hline D-Sorbitol & - & - & - \\
\hline Inulin & - & + & + \\
\hline Glycerol & + & - & + \\
\hline Sodium acetate & - & - & - \\
\hline Disodium fumarate & + & + & + \\
\hline Trisodium citrate & - & - & - \\
\hline Disodium succinate & + & + & + \\
\hline Sodium benzoate & - & - & - \\
\hline
\end{tabular}

analysis. Reference strains for FAME analysis included Nocardioides albus KCTC 9186 ${ }^{\mathrm{T}}$, Nocardioides jensenii KCTC 9134 ${ }^{\mathrm{T}}$, Nocardioides luteus KCTC 9575 ${ }^{\mathrm{T}}$, Nocardioides simplex KCTC $9106^{\mathrm{T}}$, Nocardioides pyridinolyticus KCTC 0074BP', ' $N$. fulvus' JCM 3335', Aeromicrobium erythreum NRRL B-3381 ${ }^{\mathrm{T}}$, Aeromicrobium fastidiosum KCTC $9576^{\mathrm{T}}$ and Terrabacter tumescens $\mathrm{KCTC}$ $9133^{\mathrm{T}}$.

Morphological and physiological tests. The morphology of cells was examined by light microscopy and scanning electron microscopy. Catalase activity was determined by bubble formation in a $3 \%$ hydrogen peroxide solution. Oxidase activity was determined by oxidation of $1 \%$ tetramethyl-p-phenylenediamine. Hydrolyses of gelatin, casein and starch, and production of urease were determined as described by Cowan \& Steel (1965). Hydrolyses of aesculin and arbutin were determined according to the method of Kurup \& Fink (1975). Hydrolysis of elastin was determined according to the method of Williams et al. (1983). Tests for utilization of various substrates as sole carbon and energy sources were performed as described by Shirling \& Gottlieb (1966) except that $\mathrm{CuSO}_{4}$ was not included in the trace salts solution. Most of the substrates were tested at a concentration of $1 \%(\mathrm{w} / \mathrm{v})$; the exception was glycerol $(0.1 \%$, $\mathrm{w} / \mathrm{v}$ ). The utilization results from the two strains were checked over 4 weeks.

Isolation of DNA. Chromosomal DNA was isolated and purified according to the method described previously (Yoon et al., 1996).

Chemotaxonomic characterizations. The diamino acid of the peptidoglycan was determined by the method described previously (Komagata \& Suzuki, 1987). The amino acid molar ratio of the peptidoglycan was determined as described previously (Sasaki et al., 1998). Menaquinones were analysed as described previously (Komagata \& Suzuki, 1987) using reversed-phase HPLC. Fatty acids were extracted and analysed according to the instructions of the Microbial Identification System (MIDI; Microbial ID). Polar lipids were extracted and analysed by the procedure described by Minnikin et al. (1984).

Determination of $\mathbf{G}+\mathbf{C}$ content. The $\mathbf{G}+\mathbf{C}$ content was determined by the method of Tamaoka \& Komagata (1984). DNA was hydrolysed and dephosphorylated, and the resulting nucleosides were analysed by reversed-phase HPLC.

DNA-DNA hybridization. DNA-DNA hybridization to determine genomic relatedness was performed by the dot-blot 
Table 2. Cellular fatty acid profiles of 'Nocardioides fulvus' IFO 14399, Nocardioides sp. ATCC 39419, representatives of the genera Nocardioides, Aeromicrobium species and Terrabacter tumescens

Species: 1, Nocardioides albus $\mathrm{KCTC} 9186^{\mathrm{T}} ; 2$, Nocardioides jensenii $\mathrm{KCTC} 9134^{\mathrm{T}} ; 3$, Nocardioides luteus $\mathrm{KCTC} 9575^{\mathrm{T}} ; 4$,

Nocardioides simplex KCTC 9106 ${ }^{\mathrm{T}}$; 5, Nocardioides pyridinolyticus $\mathrm{KCTC} 0074 \mathrm{BP}^{\mathrm{T}}$; 6, 'Nocardioides fulvus' JCM 3335' ; 7 ,

'Nocardioides fulvus' IFO 14399; 8, Nocardioides sp. ATCC 39419; 9, Aeromicrobium erythreum NRRL B-3381' ; 10,

Aeromicrobium fastidiosum KCTC $9576^{\mathrm{T}}$; 11, Terrabacter tumescens $\mathrm{KCTC} 9133^{\mathrm{T}}$.

\begin{tabular}{|c|c|c|c|c|c|c|c|c|c|c|c|}
\hline & 1 & 2 & 3 & 4 & 5 & 6 & 7 & 8 & 9 & 10 & 11 \\
\hline \multicolumn{12}{|l|}{ Saturated fatty acids } \\
\hline $\mathrm{C}_{14: 0}$ & & & & & & & & $0 \cdot 6$ & 0.7 & 0.6 & $7 \cdot 0$ \\
\hline $\mathrm{C}_{15: 0}$ & 0.7 & 0.3 & & & 0.4 & $0 \cdot 3$ & & $2 \cdot 2$ & 1.7 & $1 \cdot 0$ & $4 \cdot 9$ \\
\hline$C_{16: 0}^{10.0}$ & 0.7 & $1 \cdot 3$ & 0.6 & $1 \cdot 1$ & $1 \cdot 2$ & & $0 \cdot 6$ & $1 \cdot 1$ & $20 \cdot 0$ & $10 \cdot 1$ & $12 \cdot 5$ \\
\hline $\mathrm{C}_{17: 0}$ & 1.5 & $2 \cdot 7$ & 0.5 & & $1 \cdot 2$ & & & 1.8 & $2 \cdot 4$ & $2 \cdot 1$ & $5 \cdot 3$ \\
\hline $\mathrm{C}_{18: 0}$ & & $2 \cdot 0$ & & $1 \cdot 3$ & $1 \cdot 0$ & & & & $6 \cdot 1$ & $9 \cdot 7$ & $7 \cdot 8$ \\
\hline $\mathrm{C}_{19: 0}$ & & & & & & & & & & & $1 \cdot 6$ \\
\hline $\mathrm{C}_{20: 0}$ & & & & & & & & & & & \\
\hline \multicolumn{12}{|l|}{ Unsaturated fatty acids } \\
\hline $\mathrm{C}_{15: 1} \omega 6 c$ & & 0.3 & & & & $0 \cdot 8$ & 0.8 & $3 \cdot 8$ & & & 0.9 \\
\hline $\mathrm{C}_{16: 1} \omega 9 c$ & & & & & & & & & 0.8 & $1 \cdot 4$ & $0 \cdot 3$ \\
\hline$C_{17: 1}^{10.1} \omega 6 c$ & $15 \cdot 6$ & $5 \cdot 2$ & 15.9 & $13 \cdot 1$ & & $14 \cdot 9$ & 1.7 & & 0.6 & & \\
\hline $\mathrm{C}_{17: 1} \omega 8 c$ & $2 \cdot 8$ & $3 \cdot 4$ & $1 \cdot 1$ & $2 \cdot 3$ & 1.7 & $1 \cdot 0$ & $3 \cdot 7$ & $5 \cdot 5$ & $0 \cdot 8$ & & 5.8 \\
\hline $\mathrm{C}_{17: 1} \omega 9 c$ & & & & & & & & & & $0 \cdot 9$ & \\
\hline $\mathrm{C}_{18: 1} \omega 9 c$ & & $3 \cdot 3$ & & $7 \cdot 3$ & $2 \cdot 0$ & & 1.7 & & $25 \cdot 6$ & $25 \cdot 1$ & $13 \cdot 9$ \\
\hline $\mathrm{C}_{19: 1}$ iso $\mathrm{I}^{*}$ & & & & $1 \cdot 6$ & & & & & & & \\
\hline \multicolumn{12}{|l|}{ Branched fatty acids } \\
\hline iso- $\mathrm{C}_{13: 0}$ & & & & & & & & $0 \cdot 7$ & & & \\
\hline iso- $\mathrm{C}_{14: 0}$ & $2 \cdot 2$ & $1 \cdot 1$ & 0.7 & $1 \cdot 6$ & $0 \cdot 5$ & $2 \cdot 5$ & $9 \cdot 1$ & $14 \cdot 8$ & & & $4 \cdot 3$ \\
\hline iso- $\mathrm{C}_{14: 0} 3-\mathrm{OH}$ & & & 0.6 & & & & & 0.9 & & & \\
\hline iso- $\mathrm{C}_{15: 0}$ & $3 \cdot 1$ & $3 \cdot 7$ & 3.7 & $1 \cdot 5$ & $5 \cdot 1$ & $4 \cdot 1$ & $5 \cdot 4$ & $11 \cdot 2$ & & & $8 \cdot 3$ \\
\hline anteiso- $\mathrm{C}_{15: 0}$ & & & & & $1 \cdot 4$ & $0 \cdot 7$ & $24 \cdot 9$ & $35 \cdot 5$ & & & $2 \cdot 1$ \\
\hline iso- $\mathrm{C}_{16: 1} \mathrm{H}^{*}$ & $1 \cdot 1$ & $14 \cdot 0$ & $2 \cdot 1$ & $5 \cdot 4$ & $4 \cdot 2$ & $4 \cdot 7$ & $13 \cdot 5$ & $2 \cdot 9$ & & & 1.0 \\
\hline iso- $\mathrm{C}_{16: 0}$ & $53 \cdot 6$ & $45 \cdot 5$ & $49 \cdot 1$ & $33 \cdot 7$ & $47 \cdot 3$ & 57.9 & 20.9 & $8 \cdot 1$ & $1 \cdot 4$ & & $5 \cdot 6$ \\
\hline iso- $\mathrm{C}_{17: 0}$ & $1 \cdot 3$ & $1 \cdot 7$ & $1 \cdot 0$ & $2 \cdot 2$ & $1 \cdot 7$ & 0.4 & & 1.9 & & & \\
\hline iso- $\mathrm{C}_{17: 1} \omega 9 c$ & & & & & & & 6.7 & $4 \cdot 4$ & $0 \cdot 4$ & 0.7 & \\
\hline anteiso- $\mathrm{C}_{17: 1} \omega 9 c$ & & & & & $2 \cdot 12$ & & $1 \cdot 1$ & & & & \\
\hline anteiso- $\mathrm{C}_{17: 0}$ & 0.7 & 0.7 & 1.4 & $0 \cdot 5$ & $14 \cdot 2$ & $1 \cdot 1$ & $3 \cdot 2$ & $1 \cdot 3$ & & & $1 \cdot 1$ \\
\hline iso- $\mathrm{C}_{18: 0}$ & 0.9 & $2 \cdot 7$ & & 0.9 & 0.5 & & & & $0 \cdot 5$ & & \\
\hline \multicolumn{12}{|l|}{ 10-Methyl-fatty acids } \\
\hline $\mathrm{C}_{16: 0}$ & 1.5 & $2 \cdot 5$ & $5 \cdot 0$ & $4 \cdot 0$ & $5 \cdot 0$ & $3 \cdot 6$ & & & & & $2 \cdot 8$ \\
\hline $\mathrm{C}_{17: 0}$ & $12 \cdot 2$ & $5 \cdot 4$ & $15 \cdot 0$ & $5 \cdot 4$ & $5 \cdot 5$ & $6 \cdot 3$ & $3 \cdot 3$ & & $0 \cdot 3$ & & $1 \cdot 2$ \\
\hline $\mathrm{C}_{18: 0}$ & $2 \cdot 3$ & $2 \cdot 4$ & $2 \cdot 9$ & $9 \cdot 3$ & 3.4 & $1 \cdot 0$ & & & $24 \cdot 2$ & $32 \cdot 9$ & $1 \cdot 0$ \\
\hline \multicolumn{12}{|l|}{ Hydroxy fatty acids } \\
\hline $\mathrm{C}_{15: 0} 2-\mathrm{OH}$ & & & & & & & & & $0 \cdot 6$ & $0 \cdot 6$ & \\
\hline $\mathrm{C}_{16: 0} 2-\mathrm{OH}$ & & & & $0 \cdot 7$ & & & & & $11 \cdot 3$ & 8.9 & \\
\hline $\mathrm{C}_{17: 0} 2-\mathrm{OH}$ & & & & & & & & & $0 \cdot 9$ & 1.5 & \\
\hline $\mathrm{C}_{18: 0} 2-\mathrm{OH}$ & & & & & & & & & $1 \cdot 1$ & $3 \cdot 7$ & \\
\hline \multicolumn{12}{|l|}{ Summed features $\dagger$} \\
\hline Summed feature 4 & & $1 \cdot 2$ & & $5 \cdot 1$ & $0 \cdot 8$ & $0 \cdot 7$ & $3 \cdot 6$ & $2 \cdot 8$ & & $0 \cdot 9$ & $8 \cdot 1$ \\
\hline Summed feature 5 & & & & & & & & 0.7 & & & \\
\hline Summed feature 6 & & & & $0 \cdot 7$ & & & & & & & $1 \cdot 7$ \\
\hline Summed feature 7 & & & & $2 \cdot 4$ & & & & & & & 1.0 \\
\hline Summed feature 8 & & & & & 0.5 & & & & & & 1.9 \\
\hline
\end{tabular}

* The double bond position indicated by a capital letter is unknown.

$\dagger$ Summed features represent groups of two or three fatty acids which could not be separated by GLC with the MIDI system. Summed feature 4 contained one or more of following fatty acids: 15:0 iso 2-OH and/or 16:1 $1 \omega 7 c$. Summed feature 5 contained one or more of the following fatty acids: 17:1 anteiso B and/or 17:1 anteiso I. Summed feature 6 contained one or more of following fatty acids: 18:0 anteiso and/or 18:2 $266,9 \mathrm{c}$. Summed feature 7 contained one or more of following fatty acids: $18: 1$ $\omega 7 c, 18: 1 \omega 9 t$ and/or 18: $1 \omega 12 t$. Summed feature 8 contained one or more of following fatty acids: unknown fatty acid

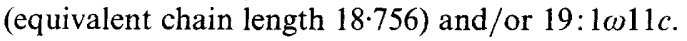


hybridization method. Labelling of probe and visualization of hybridized DNA were performed by using a nonradioactive ECL (enhanced chemiluminescence) direct nucleic acid labelling and detection system (Amersham). Resultant quantitative DNA-DNA relatedness was determined by using a densitometer (Bio-Rad).

165 rDNA sequencing. 16S rDNA sequencing from the two strains was described previously (Yoon et al., 1998a).

Phylogenetic analysis. The 16S rDNA sequences of ' $N$. fulvus' IFO 14399 and Nocardioides sp. ATCC 39419 were aligned with the 16S rRNA/16S rDNA sequences of representatives of the genus Nocardioides and some other actinomycete taxa by using CLUSTAL w software (Thompson et al., 1994). The 16S rDNA sequences of representatives of the genera Nocardioides and Aeromicrobium and of Terrabacter tumescens were determined from our recent study (Yoon et al., 1998a) and other reference sequences were obtained from the GenBank database, where the nucleotide sequences are available under the following accession numbers: X72377 (Sporichthya polymorpha), Z78207 (Microlunatus phosphovorus), Z78208 (Luteococcus japonicus), Z78206 (Friedmanniella antarctica), D85486 (Intrasporangium calvum), X87110 (Kineosporia aurantiaca), Y11928 (Terracoccus luteus), X53217 (Propionibacterium freudenreichii), X53218 (Propionibacterium acnes), M23411 (Arthrobacter globiformis), X53163 (Streptomyces albus) and Z36934 (Nocardia asteroides). The 16S rRNA sequence of Propioniferax innocua was obtained from the study of Pitcher \& Collins (1991). The 16S rDNA similarity values were calculated from the alignment and the evolutionary distances were calculated by using Kimura two-parameter correction with the CLUSTAL W software (Thompson et al., 1994). A phylogenetic tree was constructed by using the neighbour-joining method (Saitou \& Nei, 1987) on the basis of distance matrix data.

\section{RESULTS}

\section{Morphological and physiological characters}

'N. fulvus' IFO 14399 and Nocardioides sp. ATCC 39419 exhibited mycelial structures on most media. Mycelial structures were observed best on ISP agar medium no. 3 (oatmeal agar). Vegetative mycelia showed hyphae which were extensively branched and penetrated into agar media; they often fragmented into rod- to coccoid-shaped and rod elements. Aerial mycelia consisted of hyphae that fragmented into short to elongated rod-like elements (Fig. 1). Colonies of ' $N$. fulvus' IFO 14399 and Nocardioides sp. ATCC 39419 were pasty and had lichenous shapes with irregular edges. The two strains are strictly aerobic, Gram-variable and non-acid-fast. They showed catalase, oxidase and urease activities. Arbutin, casein, elastin, aesculin and Tween 80 were hydrolysed. Starch was not hydrolysed by ' $N$. fulvus' IFO 14399 and was weakly hydrolysed by Nocardioides sp. ATCC 39419. The utilization of various compounds as sole carbon and energy source is shown in Table 1, in which results from the two strains are compared with those of $N$. albus KCTC $9186^{\mathrm{T}}$, the type species of the genus Nocardioides. ' N. fulvus' IFO 14399 grew very slowly in this test. ' $N$. fulvus' IFO 14399 and Nocardioides sp. ATCC 39419 grew at pH 5 and 9. The two strains grew at 20 and $37{ }^{\circ} \mathrm{C}$. However, they grew weakly at $40^{\circ} \mathrm{C}$ and did not grow at $45^{\circ} \mathrm{C}$.

\section{Chemotaxonomic characters and DNA base compositions}

' $N$. fulvus' IFO 14399 and Nocardioides sp. ATCC 39419 have LL-diaminopimelic acid as the diamino acid in their cell wall peptidoglycan, indicating that the two strains are members of wall chemotype I (Lechevalier \& Lechevalier, 1970). The peptidoglycan of the two strains showed a similar molar ratio of amino acids D-glutamic acid:glycine:L-alanine:D-alanine:LL- $A_{2} \mathrm{pm}$ of $1: 1$ : $1: 0 \cdot 5: 0 \cdot 63$. The presence of sufficient amounts of L-alanine in the peptidoglycan strongly suggests that the two strains have L-alanine at position 1 of the peptide subunit. The predominant menaquinone found in the two strains is a tetrahydrogenated menaquinone with nine isoprenoid units $\left[\mathrm{MK}-9\left(\mathrm{H}_{4}\right)\right]$. The major cellular fatty acid of the two strains is anteiso- $\mathrm{C}_{15: 0}$, which is a minor component of members of genus Nocardioides. On the other hand, 'N. fulvus' IFO 14399 was also found to have significant amounts of iso- $\mathrm{C}_{16: 0}$ and iso- $\mathrm{C}_{16: 1} \mathrm{H}$, whereas Nocardioides $\mathrm{sp}$. ATCC 39419 had significant amounts of iso- $\mathrm{C}_{14: 0}$ and iso- $C_{15: 0}$ (Table 2). Two-dimensional TLC of polar lipids indicated the presence of phophatidylcholine and the absence of phosphatidylethanolamine. The genomic DNA $G+C$ contents of ' $N$. fulvus' IFO 14399 and Nocardioides sp. ATCC 39419 are 70 and 68 mol \%, respectively.

\section{Phylogenetic analysis}

The nearly complete nucleotide sequences of $16 \mathrm{~S}$ rDNAs from the two strains were determined directly, following PCR amplification. The sequences of the 16S rDNAs determined from ' $N$. fulvus' IFO 14399 and Nocardioides sp. ATCC 39419 were 1472 and $1470 \mathrm{bp}$, respectively, which corresponds to the regions between positions 28 and 1524 by comparison with the 16S rDNA of Escherichia coli. The 16S rDNA sequences of the two strains were compared with $16 \mathrm{~S}$ rDNA and 16S rRNA sequences of representatives of the genus Nocardioides and some other actinomycete taxa, mainly those containing LL-diaminopimelic acid in the cell wall. ' $N$. fulvus' IFO 14399 showed levels of 16S rDNA similarity of $91.4 \%$ to ' $N$. fulvus' JCM $3335^{\mathrm{T}}, 91 \cdot 3-93.5 \%$ to type strains of the genus Nocardioides, and 93-94.4\% to two Aeromicrobium species. Nocardioides sp. ATCC 39419 showed levels of $16 \mathrm{~S}$ rDNA similarity of $91 \cdot 3-93 \cdot 5 \%$ to type strains of the genus Nocardioides and $93 \cdot 3-94.5 \%$ to two Aeromicrobium species. The level of $16 \mathrm{~S}$ rDNA similarity between ' $N$. fulvus' IFO 14399 and Nocardioides sp. ATCC 39419 was $99 \%$. The phylogenetic positions of ' $N$. fulvus' IFO 14399 and Nocardioides sp. ATCC 39419 relative to members of the genera Nocardioides and Aeromicrobium and some other actinomycete taxa are shown in the tree constructed by the neighbourjoining method (Fig. 2). 


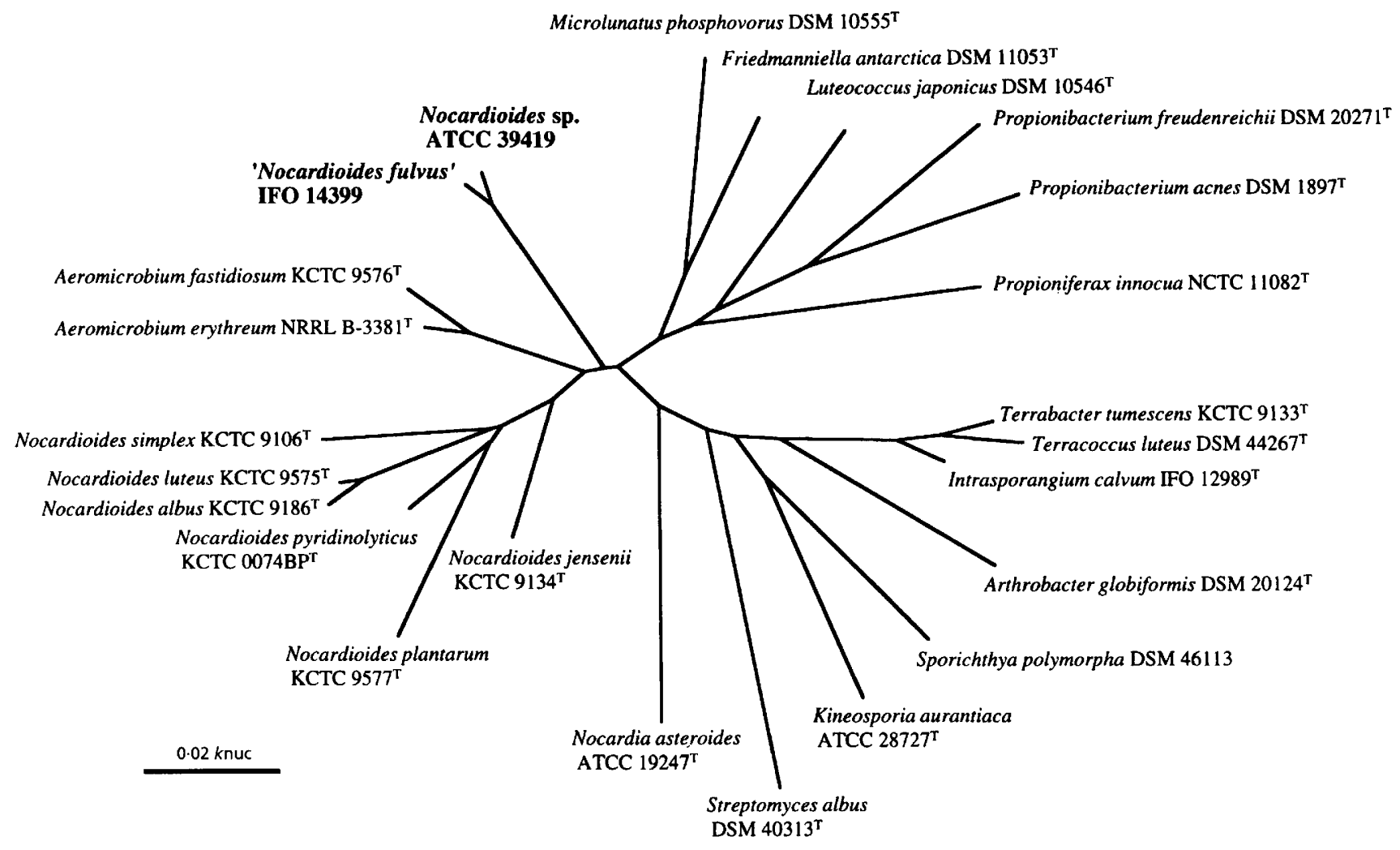

Fig. 2. Unrooted phylogenetic tree showing the positions of 'Nocardioides fulvus' IFO 14399, Nocardioides sp. ATCC 39419, LL-diaminopimelic acid-containing actinomycete taxa and some other actinomycete taxa.

\section{DNA-DNA relatedness}

The percentage DNA-DNA relatedness was $43 \%$ for ' $N$. fulvus' IFO 14399 and Nocardioides sp. ATCC 39419. 'N. fulvus' IFO 14399 and Nocardioides sp. ATCC 39419 exhibited levels of DNA-DNA relatedness of $38 \%$ and $32 \%$, respectively, to $N$. albus KCTC $9186^{\mathrm{T}}$, the type species of the genus Nocardioides, which was used as reference strain.

\section{DISCUSSION}

Two 'Nocardioides fulvus' strains were proposed by Ruan \& Zhang (1979). In our recent 16S rDNA sequence analysis (Yoon et al., 1998a), ' $N$. fulvus' JCM $3335^{\mathrm{T}}$ (strain 71-N86 ${ }^{\mathrm{T}}$ ) showed 16S rDNA sequences identical to that of $N$. luteus $\mathrm{KCTC} 9575^{\mathrm{T}}$, whereas ' $N$. fulvus' IFO 14399 (strain 65-N86) showed a low level of $16 \mathrm{~S}$ rDNA similarity of $91.3-93.5 \%$ to ' $N$. fulvus' JCM $3335^{\mathrm{T}}$ and the type strains of the genus Nocardioides. ' $N$. fulvus' IFO 14399 showed its highest level of $16 \mathrm{~S}$ rDNA similarity of $99 \%$ to Nocardioides sp. ATCC 39419, which also showed low levels of $16 \mathrm{~S}$ rDNA similarity of $91.3-93.5 \%$ to the type strains of the genus Nocardioides. This observation led us to examine the exact taxonomic positions of ' $N$. fulvus' IFO 14399 and Nocardioides sp. ATCC 39419 by using additional taxonomic traits such as phenotypic, particularly chemotaxonomic, characters.
' $N$. fulvus' IFO 14399 and Nocardioides sp. ATCC 39419 had LL-diaminopimelic acid as the diamino acid in the cell wall peptidoglycan. The major menaquinone found in ' $N$. fulvus' IFO 14399 and Nocardioides sp. ATCC 39419 was tetrahydrogenated menaquinone with nine isoprenoid units $\left[\mathrm{MK}-9\left(\mathrm{H}_{4}\right)\right]$, whereas the genus Nocardioides contains a tetrahydrogenated menaquinone with eight isoprenoid units $\left[\mathrm{MK}-8\left(\mathrm{H}_{4}\right)\right]$ (O'Donnell et al., 1982; Tamura \& Yokota, 1994). The actinomycete genera which contain $\mathrm{MK}-9\left(\mathrm{H}_{4}\right)$ as the major menaquinone among LL-A $\mathrm{A}_{2}$ pm-containing taxa include Aeromicrobium, Friedmanniella, Luteococcus, Microlunatus, Propioniferax and representatives of the genus Propionibacterium (Schumann et al., 1997).

Cellular fatty acid profiles show that ' $N$. fulvus' IFO 14399 and Nocardioides sp. ATCC 39419 are clearly distinguishable from the members of the genus Aeromicrobium as well as the genus Nocardioides. The genus Nocardioides has significant amounts of iso- $\mathrm{C}_{16: 0}$ and 10-methyl branched acids as its major fatty acids, and the genus Aeromicrobium has significant amounts of $\mathrm{C}_{16: 0}, \mathrm{C}_{18: 1}$, and 10-methyl- $\mathrm{C}_{18: 0}$ as its major fatty acids. However, the major fatty acid found in ' $N$. fulvus' IFO 14399 and Nocardioides sp. ATCC 39419 is anteiso- $C_{15: 0}$, which is scarcely detected in the members of the genera Nocardioides and Aeromicrobium (Table 2). 'N. fulvus' IFO 14399 and 
Table 3. Differential characteristics of 'Nocardioides fulvus' IFO 14399, Nocardioides sp. ATCC 39419 and LL- $\mathrm{A}_{2} \mathrm{pm}$-containing related taxa

Data for LL-A $\mathrm{A}_{2}$ pm-containing related taxa are from Schumann et al. (1997).

\begin{tabular}{|c|c|c|c|c|c|}
\hline Taxon & $\begin{array}{c}\text { Cell } \\
\text { morphology }\end{array}$ & $\begin{array}{c}\text { Major } \\
\text { menaquinone(s) }\end{array}$ & $\begin{array}{l}\text { Amino acid at } \\
\text { position } 1 \text { of } \\
\text { peptide subunit }\end{array}$ & Polar lipids* & $\begin{array}{c}\mathbf{G}+\mathbf{C} \text { content } \\
\quad(\mathrm{mol} \%)\end{array}$ \\
\hline $\begin{array}{l}\text { Strains IFO } 14399 \text { and } \\
\text { ATCC } 39419\end{array}$ & Hyphae & MK-9( $\left.\mathrm{H}_{4}\right)$ & L-Alanine & $\mathrm{PC}$ & $68-70$ \\
\hline Nocardioides albus & Hyphae & MK- $8\left(\mathrm{H}_{4}\right)$ & L-Alanine & PG, DPG, PL, PG-OH & $66 \cdot 5-68 \cdot 6$ \\
\hline Nocardioides simplex & Rods, cocci & $\mathrm{MK}-8\left(\mathrm{H}_{4}\right)$ & LyAlanine & PG, DPG, PL, PG-OH & $71 \cdot 7$ \\
\hline Aeromicrobium & Rods & MK-9(- $\left.\mathrm{H}_{4}\right)$ & L-Alanine & PE, PG & $71-73$ \\
\hline Friedmanniella & Cocci in packets & MK-9 $\left(\mathrm{H}_{4}\right)$ & Glycine & PI, PG, DPG, PL & 73 \\
\hline Luteococcus & Cocci & MK-9(- $\left.\mathrm{H}_{4}\right)$ & L-Alanine & PI, PG, DPG, GL & $66-68$ \\
\hline Microlunatus & Cocci & MK-9(- $\left.\mathrm{H}_{4}\right)$ & Glycine & PI, PG, DPG, PL & $67 \cdot 9$ \\
\hline Propioniferax & Rods & MK-9 $\left(\mathrm{H}_{4}\right)$ & L-Alanine & PE, PG, PL, GL & $59-63$ \\
\hline $\begin{array}{l}\text { Propionibacterium } \\
\text { propionicum }\end{array}$ & Pleomorphic & MK-9(H $\left.\mathrm{H}_{4}\right)$ & Glycine & $\mathrm{ND}$ & $63-65$ \\
\hline Terrabacter & Rods, cocci & MK-8 $\left(\mathrm{H}_{4}\right)$ & L-Alanine & PE, PI, DPG, PL & $69 \cdot 8-73 \cdot 4$ \\
\hline Terracoccus & Cocci & $\mathrm{MK}-8\left(\mathrm{H}_{4}\right)$ & Glycine & PE, PI, PG, DPG & 73 \\
\hline Intrasporangium & Hyphae & MK-8 & L-Alanine & PI, PIM, PG, DPG & $68 \cdot 2$ \\
\hline Sporichthya & Hyphae & MK-9 $\left(\mathrm{H}_{6}\right)$, MK-9 $\left(\mathrm{H}_{8}\right)$ & L-Alanine & PI, PG, DPG, PL & $70 \cdot 1$ \\
\hline Streptomyces & Hyphae & MK-9(- $\left.\mathrm{H}_{6}\right)$, MK- $-9\left(\mathrm{H}_{8}\right)$ & L-Alanine & PE, PI, PIM, DPG & $69-73$ \\
\hline
\end{tabular}

* DPG, diphosphatidylglycerol; GL, unknown glycolipid(s); PC, phosphatidylcholine; PE, phosphatidylethanolamine; PG, phosphatidylglycerol; PG-OH, phosphatidylglycerol containing 2-hydroxy fatty acids; PI, phosphatidylinositol; PL, unknown phospholipid(s); ND, not determined.

Nocardioides sp. ATCC 39419 are also distinguished from the genera Luteococcus, Friedmanniella, Microlunatus and Propioniferax, which have only single species, by cellular fatty acid profiles. The genus Luteococcus has significant amounts of $\mathrm{C}_{17: 1}$ and $\mathrm{C}_{16: 1}$ as its major fatty acids (Schumann et al., 1997). The genera Friedmanniella, Microlunatus and Propioniferax have anteiso- $\mathrm{C}_{15: 0}$ as the major fatty acid (Schumann et al., 1997), which is the same as that of ' $N$. fulvus' IFO 14399 and Nocardioides sp. ATCC 39419. However, apart from the major fatty acids, the rest of the fatty acid profiles of the three genera are different from those of ' $N$. fulvus' IFO 14399 and Nocardioides sp. ATCC 39419, although standardized conditions between them were not used. The three genera have iso- $\mathrm{C}_{15: 0}$ as the second most predominant fatty acid and other fatty acids exist only in minor amounts (Schumann et al., 1997). However, 'N. fulvus' IFO 14399 had significant amounts (more than 10\%) of iso- $\mathrm{C}_{16: 0}$ and iso- $\mathrm{C}_{16: 1} \mathrm{H}$, and Nocardioides sp. ATCC 39419 had significant amounts (more than $10 \%$ ) of iso- $\mathrm{C}_{14: 0}$ and iso- $\mathrm{C}_{15: 0}$ (Table 2). Diagnostic polar lipid profiles also show that ' $N$. fulvus' IFO 14399 and Nocardioides sp. ATCC 39419 differ from other LL-A $\mathrm{A}_{2} \mathrm{pm}$-containing taxa in the presence of phosphatidylcholine (Table 3). Considering that phosphatidylcholine has been not found in the other

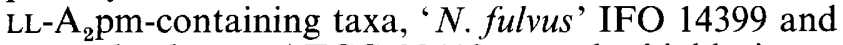
Nocardioides sp. ATCC 39419 must be highly interesting taxa.
' $N$. fulvus' IFO 14399 and Nocardioides sp. ATCC 39419 are also different from other taxa containing LL- $\mathrm{A}_{2} \mathrm{pm}$ and MK-9 $\left(\mathrm{H}_{4}\right)$ in showing hyphal morphology. The genera Aeromicrobium, Friedmanniella, Luteococcus, Microlunatus and Propioniferax do not form mycelial structures and their cells are cocci or rods (Schumann et al., 1997). Among existing taxa containing LL-A ${ }_{2}$ pm and MK-9(H4) only Propionibacterium propionicum shows a cellular structure of branching filaments (Charfreitag et al., 1988), but this can be differentiated from ' $N$. fulvus' IFO 14399 and Nocardioides sp. ATCC 39419 by the different amino acid at position 1 of the peptide subunit (Table 3).

Despite the similarity of several chemotaxonomic characters between ' $N$. fulvus' IFO 14399 and $N o$ cardioides sp. ATCC 39419 and some genera containing LL-diaminopimelic acid, in particular, the genera Friedmanniella, Microlunatus and Propioniferax, they are phylogenetically distinct from each other. The phylogenetic tree shows that ' $N$. fulvus' IFO 14399 and Nocardioides sp. ATCC 39419 form a phylogenetic lineage distinct from other LL-diaminopimelic-acid-containing taxa and some other actinomycete taxa (Fig. 2). Nevertheless, ' $N$. fulvus' IFO 14399 and Nocardioides sp. ATCC 39419 are thought to form phylogenetic lineages that are related to the genera Nocardioides and Aeromicrobium, which are members of the family Nocardioidaceae (Stackebrandt et al., 1997). The amino acid at position 1 of the 
peptide subunit of the peptidoglycan supports the contention that ' $N$. fulvus' IFO 14399 and $N o$ cardioides sp. ATCC 39419 are more closely related to the genera Nocardioides and Aeromicrobium than to the members of the family Propionibacteriaceae (Table 3). 'N. fulvus' IFO 14399 and Nocardioides sp. ATCC 39419 and the genera Nocardioides and Aeromicrobium have L-alanine at position 1 of the peptide subunit, whereas among members of the family Propionibacteriaceae, the genera Friedmanniella and Microlunatus and $P$. propionicum have glycine at this position.

' $N$. fulvus' IFO 14399 and Nocardioides sp. ATCC 39419 are considered as different species by DNADNA relatedness and some phenotypic properties. The value of DNA-DNA relatedness for the two strains is $43 \%$. Strains with DNA-DNA relatedness less than $70 \%$ are considered as different species according to the current phylogenetic definition for a species (Wayne et al., 1987). In addition, recent studies have shown that the two strains have distinct differences in size and nucleotide similarity of the $16 \mathrm{~S}-23 \mathrm{~S}$ internally transcribed spacer (ITS) (Yoon et al., 1998b). The size of the 16S-23S ITS of ' $N$. fulvus' IFO 14399 is 473 bp long, whereas Nocardioides sp. ATCC 39419 has two types of 16S-23S ITSs on the genome, which are 429 and 439 bp long. ' $N$. fulvus' IFO 14399 exhibited levels of 16S-23S ITS nucleotide similarity of 73.6 and $75.4 \%$ to Nocardioides sp. ATCC 39419 . The two strains also showed a difference in the composition of predominant fatty acids except for the major fatty acid, and some differences in physiological characters (Table 2).

On the basis of phenotypic and phylogenetic data, ' $N$. fulvus' IFO 14399 and Nocardioides sp. ATCC 39419 should be differentiated from other genera containing LL-diaminopimelic acid in the cell wall. Also, ' $N$. fulvus' IFO 14399 and Nocardioides sp. ATCC 39419 are considered as different species by data based on DNA-DNA relatedness and differences in some phenotypic properties. Consequently, a new genus, Kribbella gen. nov., and two new species, Kribbella flavida gen. nov., sp. nov. and Kribbella sandramycini gen. nov., sp. nov., are proposed. Descriptions of these taxa are given below.

\section{Description of Kribbella gen. nov.}

Kribbella (Kribb.el'la. M.L. dim. fem. ending -ella; M.L. fem. n. Kribbella arbitrary name formed from the acronym of the Korea Research Institute of Bioscience and Biotechnology, KRIBB, where taxonomic studies of this taxon were performed).

Vegetative mycelium shows hyphae which are extensively branched and penetrate into agar media; they often fragment into rod- to coccoid-shaped and rod elements. Aerial mycelium consists of hyphae that fragment into short to elongated rod-like elements. Colonies are pasty and have lichenous shapes and irregular edges. Strictly aerobic. Gram-variable.
Non-acid-fast. Catalase-, oxidase- and ureasepositive. Contains LL-diaminopimelic acid as the diamino acid in the cell wall peptidoglycan (wall chemotype I). The predominant menaquinone is MK-9 $\left(\mathrm{H}_{4}\right)$. The fatty acid profile consists of large amounts of branched fatty acids and the major cellular fatty acid is anteiso- $\mathrm{C}_{15: 0}$. The polar lipid is phosphatidylcholine. The genomic DNA G $+\mathrm{C}$ content is $68-70 \mathrm{~mol} \%$. The type species is Kribbella flavida.

\section{Description of Kribbella flavida sp. nov.}

Kribbella flavida (fla'vi.da. L. fem. adj. flavida pale yellow).

Vegetative mycelium shows hyphae which are extensively branched and penetrate into agar media; they often fragment into rod- to coccoid-shaped and rod elements. Aerial mycelium consists of hyphae that fragment into short to elongated rod-like elements. Colonies are pasty and have lichenous shapes with irregular edges. Strictly aerobic. Gram-variable. Non-acid-fast. Catalase-, oxidase- and ureasepositive. Arbutin, casein, elastin, aesculin and Tween 80 are hydrolysed. Starch is not hydrolysed. Substrates utilized as a sole carbon and energy sources are listed in Table 1. Growth occurs at $\mathrm{pH} 5$ and 9. Growth occurs at 20 and $37^{\circ} \mathrm{C}$, occurs weakly at $40^{\circ} \mathrm{C}$ and does not occur at $45^{\circ} \mathrm{C}$. The major cellular fatty acid is anteiso- $\mathrm{C}_{15: 0}$ and significant amounts (more than $10 \%$ ) of iso- $\mathrm{C}_{16: 0}$ and iso- $\mathrm{C}_{16: 1} \mathrm{H}$ are also found. The genomic DNA $\mathrm{G}+\mathrm{C}$ content is $70 \mathrm{~mol} \%$ (as determined by HPLC). Isolated from soil. The type strain is strain IFO $14399^{\mathrm{T}}\left(=\mathrm{KCTC} 9580^{\mathrm{T}}\right)$.

\section{Description of Kribbella sandramycini sp. nov.}

Kribbella sandramycini (san.dra.my.ci'ni. M.L. n. sandramycini referring to an antibiotic, sandramycin).

Vegetative mycelium shows hyphae which are extensively branched and penetrate into agar media; they often fragment into rod- to coccoid-shaped and rod elements. Aerial mycelium consists of hyphae that fragment into short to elongated rod-like elements. Colonies are pasty and have lichenous shapes with irregular edges. Strictly aerobic. Gram-variable. Non-acid-fast. Catalase-, oxidase- and ureasepositive. Arbutin, casein, elastin, aesculin and Tween 80 are hydrolysed. Starch is weakly hydrolysed. Substrates utilized as a sole carbon and energy sources are listed in Table 1. Growth occurs at $\mathrm{pH} 5$ and 9. Growth occurs at 20 and $37^{\circ} \mathrm{C}$, occurs weakly at $40^{\circ} \mathrm{C}$ and does not occur at $45^{\circ} \mathrm{C}$. The major cellular fatty acid is anteiso- $\mathrm{C}_{15: 0}$ and significant amounts (more than $10 \%$ ) of iso- $\mathrm{C}_{14: 0}$ and iso- $\mathrm{C}_{15: 0}$ are also found. The genomic DNA $\mathrm{G}+\mathrm{C}$ content is $68.3 \mathrm{~mol} \%$ (as determined by HPLC). Isolated from a soil in Mexico. Produces an antibiotic, sandramycin. The type strain is strain ATCC $39419^{\mathrm{T}}\left(=\mathrm{KCTC} 9609^{\mathrm{T}}\right)$. 


\section{ACKNOWLEDGEMENTS}

This work was supported by Asian Network on Microbial Researches from the Science and Technology Agency of Japan and grant HS1841 from the Ministry of Science and Technology (MOST) of the Republic of Korea. We are grateful to J. L. Swezey of the ARS Patent Culture Collection, Microbial Properties Research for providing Aeromicrobium erythreum NRRL B-3381 ${ }^{\mathrm{T}}$ and to IFO (Institute for Fermentation, Osaka, Japan) for providing 'Nocardioides fulvus' IFO 14399.

\section{REFERENCES}

Charfreitag, O., Collins, M. D. \& Stackebrandt, E. (1988). Reclassification of Arachnia propionica as Propionibacterium propionicus comb. nov. Int J Syst Bacteriol 38, 354-357.

Collins, M. D., Dorsch, M. \& Stackebrandt, E. (1989). Transfer of Pimelobacter tumescens to Terrabacter gen. nov. as Terrabacter tumescens comb. nov. and of Pimelobacter jensenii to $\mathrm{No}$ cardioides as Nocardioides jensenii comb. nov. Int $J$ Syst Bacteriol 39, 1-6.

Cowan, S. T. \& Steel, K. J. (1965). Manual for the Identification of Medical Bacteria. London: Cambridge University Press.

Kalakoutskii, L. V., Kirillova, I. P. \& Krassilnikov, N. A. (1967). A new genus of the Actinomycetales - Intrasporangium gen.nov. $J$ Gen Microbiol 48, 79-85.

Komagata, K. \& Suzuki, K. (1987). Lipids and cell-wall analysis in bacterial systematics. Methods Microbiol 19, 161-203.

Kurup, V. P. \& Fink, J. N. (1975). A scheme for the identification of thermophilic actinomycetes associated with hypersensitivity pneumonitis. J Clin Microbiol 2, 55-61.

Lechevalier, M. P. \& Lechevalier, H. A. (1970). A critical evaluation of the genera of acrobic actinomycetes. In The Actinomycetales, pp. 393-405. Edited by H. Prauser. Jena: Gustav Fischer.

Lechevalier, M. P., Lechevalier, H. \& Holbert, P. E. (1968). Sporichthya, un nouveau genre de Streptomycetaceae. Ann Inst Pasteur 114, 277-286.

Lindenbein, w. (1952). Über einige chemisch interessante Actinomycetenstämme und ihre Klassifizierung. Arch Mikrobiol 17, 361-383.

Matson, J. A. \& Bush, J. A. (1989). Sandramycin, a novel antitumour antibiotic produced by a Nocardioides sp. Production, isolation, characterization and biological properties. $J$ Antibiotics 42, 1763-1767.

Miller, E. S., Woese, C. R. \& Brenner, S. (1991). Description of the erythromycin-producing bacterium Arthrobacter sp. strain NRRL B-3381 as Aeromicrobium erythreum gen. nov., sp. nov. Int J Syst Bacteriol 41, 363-368.

Minnikin, D. E., O'Donnell, A. G., Goodfellow, M., Alderson, G., Athalye, M., Schaal, A. \& Parlett, J. H. (1984). An integrated procedure for the extraction of bacterial isoprenoid quinones and polar lipids. J Microbiol Methods 2, 233-241.

Nakamura, K., Hiraishi, A., Yoshimi, Y., Kawaharasaki, M., Masuda, K. \& Kamagata, Y. (1995). Microlunatus phosphovorus gen. nov., sp. nov., a new gram positive polyphosphateaccumulating bacterium isolated from activated sludge. Int $J$ Syst Bacteriol 45, 17-22.

Nesterenko, O. A., Kvasnikov, E. I. \& Nogina, T. M. (1985).
Nocardioidaceae fam. nov., a new family of the order Actinomycetales Buchanan 1917. Microbiol Zhurnal 47, 3-12.

O'Donnell, A. G., Goodfellow, M. \& Minnikin, D. E. (1982). Lipids in the classification of Nocardioides: reclassification of Arthrobacter simplex (Jensen) Lochhead in the genus Nocardioides (Prauser) emend. O'Donnell et al. as Nocardioides simplex comb. nov. Arch Microbiol 133, 323-329.

Pitcher, D. G. \& Collins, M. D. (1991). Phylogenetic analysis of some LL-diaminopimelic acid-containing coryneform bacteria from human skin: description of Propionibacterium innocuum sp. nov. FEMS Microbiol Lett 84, 295-300.

Prauser, H. (1976). Nocardioides, a new genus of the order Actinomycetales. Int $J$ Syst Bacteriol 26, 58-65.

Prauser, H., Schumann, P., Rainey, F. A., Kroppenstedt, R. M. \& Stackebrandt, E. (1997). Terracoccus luteus gen. nov., sp. nov., an LL-diaminopimelic acid-containing coccoid actinomycete from soil. Int J Syst Bacteriol 47, 1218-1224.

Rainey, F. A., Schumann, P., Prauser, H., Toalster, R. \& Stackebrandt, E. (1993). Sporichthya polymorpha represents a novel line of descent within the order Actinomycetales. FEMS Microbiol Lett 109, 263-268.

Ruan, J. S. \& Zhang, Y. M. (1979). Two new species of Nocardioides. Acta Microbiol Sin 19, 347-352.

Saitou, N. \& Nei, M. (1987). The neighbor-joining method: a new method for reconstructing phylogenetic trees. Mol Biol Evol 4, $406-425$.

Sasaki, J., Chijimatsu, M. \& Suzuki, K. (1998). Taxonomic significance of 2,4-diaminobutyric acid isomers in the cell wall peptidoglycan of actinomycetes and reclassification of Clavibacter toxicus as Rathayibacter toxicus comb. nov. Int J Syst Bacteriol 48, 403-410.

Schumann, P., Prauser, H., Rainey, F. A., Stackebrandt, E. \& Hirsch, P. (1997). Friedmanniella antarctica gen. nov., sp. nov., an LL-diaminopimelic acid-containing actinomycete from antarctic sandstone. Int J Syst Bacteriol 47, 278-283.

Shirling, E. B. \& Gottlieb, D. (1966). Methods for characterization of Streptomyces species. Int J Syst Bacteriol 16, 313-340.

Stackebrandt, E., Rainey, F. A. \& Ward-Rainey, N. L. (1997). Proposal for a new hierarchic classification system, Actinobacteria classis nov. Int $J$ Syst Bacteriol 47, 479-491.

Suzuki, K. \& Komagata, K. (1983). Pimelobacter gen. nov., a new genus of coryneform bacteria with LL-diaminopimelic acid in the cell wall. J Gen Appl Microbiol 29, 59-71.

Tamaoka, J. \& Komagata, K. (1984). Determination of DNA base composition by reverse-phase high-performance liquid chromatography. FEMS Microbiol Lett 25, 125-128.

Tamura, T. \& Yokota, A. (1994). Transfer of Nocardioides fastidiosa Collins and Stackebrandt 1989 to the genus Aeromicrobium as Aeromicrobium fastidiosum comb. nov. Int J Syst Bacteriol 44, 608-611.

Tamura, T., Takeuchi, M. \& Yokota, A. (1994). Luteococcus japonicus gen. nov., a new gram-positive coccus with LLdiaminopimelic acid in the cell wall. Int $J$ Syst Bacteriol 44, 348-356.

Thompson, J. D., Higgins, D. G. \& Gibson, T. J. (1994). CLUSTAL W: improving the sensitivity of progressive multiple sequence alignment through sequence weighting, position-specific gap penalties and weight matrix choice. Nucleic Acids Res 22, $4673-4680$

Waksman, S. A. \& Henrici, A. T. (1943). The nomenclature and classification of the actinomycetes. $J$ Bacteriol 46, 337-341. 
Wayne, L. G., Brenner, D. J., Colwell, R. R. \& 9 other authors (1987). Report of the ad hoc committee on reconciliation of approaches to bacterial systematics. Int J Syst Bacteriol 37, 463-464.

Williams, S.T., Goodfellow, M., Alderson, G., Wellington, E. M. H., Sneath, P. H. A. \& Sackin, M. J. (1983). Numerical classification of Streptomyces and related genera. J Gen Microbiol 129, 1743-1813.

Yokota, A., Tamura, T., Takeuchi, M., Weiss, N. \& Stackebrandt, E. (1994). Transfer of Propionibacterium innocuum Pitcher and Collins 1991 to Propioniferax gen. nov., as Propioniferax innocua comb. nov. Int $J$ Syst Bacteriol 44, 579-582.
Yoon, J.-H., Kim, H., Kim, S.-B., Kim, H.-J., Kim, W. Y., Lee, S. T., Goodfellow, M. \& Park, Y.-H. (1996). Identification of Saccharomonospora strains by the use of genomic DNA fragments and rRNA gene probes. Int $J$ Syst Bacteriol 46, 502-505.

Yoon, J.-H., Lee, S. T. \& Park, Y.-H. (1998a). Inter- and intraspecific phylogenetic analysis of the genus Nocardioides and related taxa based on $16 \mathrm{~S}$ rDNA sequences. Int $J$ Syst Bacteriol 48, 187-194.

Yoon, J.-H., Lee, S. T. \& Park, Y.-H. (1998b). Genetic analyses of the genus Nocardioides and related taxa based on $16 \mathrm{~S}-23 \mathrm{~S}$ rDNA internally transcribed spacer sequences. Int $J$ Syst Bacteriol 48, 641-650. 